\title{
Seasonality in Bitcoin Market
}

\section{Ahmad Fraz', Arshad Hassan², Sumayya Chughtai ${ }^{3}$ \\ ${ }^{1}$ Assistant Professor, Department of Economics and Finance, PIDE Islamabad \\ ${ }^{2}$ Professor, Faculty of Management and Social Sciences, CUST Islamabad \\ ${ }^{3}$ Assistant Professor, Department of Accounting \& Finance, IIU Islamabad}

\section{A B S T R A C T}

Bitcoin is an online communication protocol, which facilitates electronic transactions. It has grabbed the attention of investors and researchers in the recent past. The non-regulatory feature of Bitcoin makes it riskier and the element of speculation in its trading is higher than any other financial asset. The study provides an insight into the price dynamics of Bitcoin by examining the day of the week and month of the year effect for the period 2013 to 2017 . The findings of the study indicate the existence of seasonality in the return behaviour of Bitcoin as returns for Monday is higher than any other day of the week. Likewise, the returns earned during the month of November are significantly different from other months of the year. The results of the study assert a violation of the assumption of weak-form market efficiency and imply that the Bitcoin market provides an opportunity for the investors to exploit the market from its predictable behavior and fetch abnormal gains.

JEL Classification- E44, G14,

Keywords: Bitcoin, Crypto-currency, Market efficiency, Calendar Anomalies, Abnormal returns

\section{INTRODUCTION}

The seminal work Bachelier (1900) has provided the foundation stone for academicians and analysts in examining the randomness of the return generation process in the stock markets. The main concern raised by researchers about the return generation process is whether this process is continuous (Fama, 1965) or operates during the active trading time (Clark, 1973). In general, most of the stock markets follow a trading calendar of five days a week i.e. from Monday to Friday. It suggests that if the return generation process is continuous, the distribution of Monday's returns will be different from the rest of the days of the week and if the process follows trading time, the distribution of returns for all days of the week will be same (French, 1980). 
A number of studies suggest that return distribution of stocks varies on a particular day of the week and month of the year (Clark, 1973; Cross, 1973; Robins \& Smith, 2017; Fama, 1965). Such seasonal patterns indicate violations of the Efficient Market Hypothesis (EMH hereafter). Moreover, such anomalous behavior is also observed in the foreign currency market. Aydoğan and Booth (2010) report the presence of the day of the week effect in Turkish foreign currency market. Yamori and Kurihara (2004) argue that currency markets are directly involved in the transactions and also use currency as assets in the form of deposits. Furthermore, the study reports that the day of the week effect existed in the 1980s and disappeared after the 1990s.

The stock markets and currency markets are deemed as major financial assets classes for portfolio investors. Over some time, the crypto-currency market has also emerged as a new financial asset class. It is a form of cryptocurrency based on a decentralized monetary system which was first introduced by Satoshi Nakamoto in 2009. It has gained the attention of investors, media, and academicians over a shorter period. Interestingly, the investors consider Bitcoin as a medium of exchange like a currency as well as an investment option simultaneously (Selgin, 2015). Being a decentralized and relatively new market, there is a high probability of observing seasonality patterns in returns of Bitcoin. Such seasonal patterns like calendar anomalies provide an opportunity for an investor to earn abnormal returns.

A vast body of literature reports presence and persistence of calendar anomalies and provides evidence of rejection of EMH in the equity market and foreign currency market (Fama, 1965; Clark, 1973; Aydoğan \& Booth, 2010; Fraz \& Hassan, 2016; Robins \& Smith, 2017). The objective of this study is to investigate the seasonality in the Bitcoin market as it provides diversification opportunity to the investor (Glaser et al, 2014). This market is also different concerning its trading time. The trading activities continue five days a week in a conventional stock market, whereas in crypto-currency markets trading continues 24/7. This study investigates the continuous returns generation process by analyzing the day of the week and month of the year effect for the Bitcoin market. Moreover, the study aims to provide a better understanding of resource allocation to the investors by unpacking the efficiency dynamics of the Bitcoin market. 
The rest of the paper is organized as under: the literature is critically reviewed in Section II, data and methodology adopted to analyze seasonality in returns in Section III, followed by empirical analysis in Section IV and finally the conclusion is presented in Section V.

\section{LITERATURE REVIEW}

A huge body of literature is available on examination of efficiency stock markets and currency markets while only a handful of studies are available on efficiency dynamics of crypto-currency market (French, 1980; Yamori \& Kurihara, 2004). These studies focus on the random behavior in stock prices by examining the weak form of efficiency (Fama, 1970; Aumeboonsuke \& Dryver, 2014). Following the study of French (1980), several studies confirm the effect of calendar anomalies such as day of the week effect, week of the month effect, the month of the year, change of the year effect, Islamic calendar effect, Chinese calendar effect, etc. This significant statistical difference in the returns of an asset on any particular day, week, or year is known as calendar anomaly. Berument and Kiymaz (2001) investigate the day of the week effect in the US stock market for the period of 1973 to 1997. Their findings reveal that higher returns are observed during mid of the week i.e. Wednesday and lowest returns are reported on Monday.

Kiymaz and Berument (2003) examine the day of the week effect on stock return volatility of five developed markets US, UK, Germany, Canada, and Japan from 1988 to 2002 using the GARCH model. The results of the study report on the day of the week effect in both returns and volatility of returns. The findings suggest that high volatility return days are different for every market. For instance, for markets of Germany and Japan, the highly volatile day is Monday. Similarly, for US and Canadian markets highest volatility in returns is reported on Friday and for the UK highly volatile day is Thursday. In recent years, researchers and academicians show a special interest in understanding the price dynamics of newly emerged asset Bitcoin (Katsiampa, 2017; Hencic \& Gouriéroux, 2015). Some recent studies examine the volatility in the Bitcoin market and empirically report it as a highly volatile market due to its speculative nature (Cheah \& Fry, 2015; 
Cheung, Roca, \& Su, 2015; Dyhrberg, 2016).

Kurihara (2011) investigates the market efficiency of the foreign currency market by using the GARCH model. The results indicate that in the foreign currency markets are weak-form inefficient due to the presence of Monday and Friday anomaly. Rozeff and Kinney (1976) report month of the year effect in the US stock market for the very first time. The results of the study reported significant differences in the monthly returns due to large January returns. Cooper, McConnell, and Ovtchinnikov (2006) test the January effect and findings of their study suggest that January returns have predictive power to forecast market returns for the rest of the months of the year. Earlier studies examine the day of the week effect and month of the year effect in stock markets, currency markets and commodity markets (Cooper, McConnell, \& Ovtchinnikov, 2006; Yamori \& Kurihara, 2004; Aydoğan \& Booth, 2010).

Numerous studies have investigated cryptocurrency markets, the price discovery process of the cryptocurrency market by using Bitcoin (Brandvold et al. 2015; Corbet et al. 2018), Fry and Cheah (2016) examine the bubbles in cryptocurrencies, Thies and Molnár (2018) explore the presence of structural breaks in Bitcoin. Some studies have examined the volatility dynamics of cryptocurrency prices (Katsiampa, 2017; Troster et al. 2018). These studies have reported inefficiencies in the cryptocurrency market. Bariviera (2017) has investigated market efficiency by using the long memory of Bitcoin returns under time-varying behavior by using the Hurst exponent and Detrended Fluctuation Analysis methodology. The results of the study indicate that the market is efficient. Whereas, Caporale et al. (2018) revisited four different cryptocurrencies by using long memory and fractional integration method. The results indicate the persistence of price changes in these currencies, which shows inefficiency in the market and suggests that investors can earn abnormal gains by using different trading strategies in these markets.

Although, cryptocurrency markets are quite young, a sufficient amount of data is now available for around five years to test the efficiency phenomenon. Kurihara and Fukushima (2017) investigate calendar anomaly in the cryptocurrency market for the period of 2010 to 2016. It is the only study to date that has examined the day of the week 
effect in the Bitcoin market. The results of the study suggest that the Bitcoin market is not weak form efficient. Aharon and Qadan (2018) have investigated the day of the week effect in returns and volatility of bitcoin using OLS and volatility modeling. The findings of the study suggest inefficiency in the Bitcoin market and confirm the day of the week anomaly. The global perspective requires revisiting the seasonality element in Bitcoin returns to check the market efficiency and needs further insight. Kurihara and Fukushima (2017) and Aharon and Qadan (2018) examine the only day of the week effect in the Bitcoin market. Whereas, the current study is an attempt to extend the study of Aharon and Qadan (2018) by investigating the day of the week effect along with the month of the year effect in the Bitcoin market. The current study is based on the premise that the Bitcoin being a newborn in the world of financial assets may face inefficiencies in its trading.

\section{RESEARCH METHODOLOGY}

The current study employs daily and monthly data of Bitcoin prices from May 1st, 2013 to December 31st, 2017. The daily returns are calculated on continuous compounding assumption by taking the natural log of Bitcoin price on the current day divided by the Bitcoin price on previous days i.e., $\mathrm{Ri}=\ln (\mathrm{DBt} / \mathrm{DBt}-1)$. Where $\mathrm{DBt}$ is the closing Bitcoin price on the day " $\mathrm{t}$ " and DBt-1 is the closing Bitcoin price on the day "t-1". Furthermore, the monthly returns are calculated by using monthly Bitcoin prices. Similarly, monthly returns are calculated. The data was extracted from the cryptocurrency market capitalization website.

To test day of the week and month of the year effects, the study employs the methodology used by the previous studies (French, 1980; Yamori \& Kurihara, 2004; Kurihara \& Fukushima, 2017). The following empirical models are used to check seasonality in daily data of Bitcoin.

$\mathrm{DR}_{\mathrm{t}}=\beta_{1}$ Mon $_{\mathrm{t}}+\beta_{2}$ Tue $_{\mathrm{t}}+\beta_{3}$ Wed $_{\mathrm{t}}+\beta_{4}$ Thu $_{\mathrm{t}}+\beta_{5}$ Fri $_{\mathrm{t}}+\beta_{6}$ Sat $_{\mathrm{t}}+\beta_{7}$ Sun $_{\mathrm{t}}$

Where, DRt is the daily return of Bitcoin as defined above i.e., $\ln (\mathrm{DBt} / \mathrm{DBt}-1)$. Mon is the dummy variable for Monday that is 1 if the day $t$ is Monday otherwise 0 . Tue is the dummy variable for Tuesday, Wed is the dummy variable for Wednesday, Thu is the 
dummy variable for Thursday, Fri is the dummy variable for Friday, Sat is the dummy variable for Saturday, Sun is the dummy variable for Sunday. Moreover, all dummy variables from Tuesday to Sunday are similar as defined for Monday. The seasonality in monthly data is captured by using the following model.

$\mathrm{MR}_{\mathrm{t}}=\beta_{1} \operatorname{Jan}_{\mathrm{t}}+\beta_{2} \mathrm{Feb}_{\mathrm{t}}+\beta_{3} \mathrm{Mar}_{\mathrm{t}}+\beta_{4} \mathrm{Apr}_{\mathrm{t}}+\beta_{5} \mathrm{May}_{\mathrm{t}}+\beta_{6} \mathrm{June}_{\mathrm{t}}+\beta_{7} \mathrm{Jul}_{\mathrm{t}}+$ $\beta_{8}$ Aug $_{t}+\beta_{9}$ Sep $_{t}+\beta_{10}$ Oct $_{t}+\beta_{11}$ Nov $_{t}+\beta_{12}$ Dec $_{t}$

Where MRt is the monthly return, Jan is the dummy variable for January which takes the value of 1 if month January otherwise 0 . Feb is the dummy variable for February, Mar is the dummy variable for March, Apr is the dummy variable for April, May is the dummy variable for May, Jun is the dummy variable for June, Jul is the dummy variable for July, Aug is the dummy variable for August, Sep is the dummy variable for September, Oct is the dummy variable for October, Nov is the dummy variable for November, Dec is the dummy variable for December and all dummy variables from February to December are similar as defined to January.

\section{EMPIRICAL RESULTS AND DISCUSSION}

Table 1 presents the statistical behavior of Bitcoin returns from Monday to Sunday for the period from 2013 to 2017.

Table 1: Descriptive statistics of daily Bitcoin returns for the period from 2013 to 2017

\begin{tabular}{|c|c|c|c|c|c|c|c|}
\hline & Mean & Median & Std. Dev. & Kurtosis & Skewness & Minimum & Maximum \\
\hline Monday & 0.00913 & 0.00508 & 0.04580 & 16.63119 & 1.56603 & -0.21593 & 0.35745 \\
\hline Tuesday & 0.00394 & 0.00366 & 0.04177 & 6.84134 & -1.14097 & -0.20064 & 0.14964 \\
\hline Wednesday & -0.00048 & -0.00012 & 0.04774 & 7.84298 & -1.17576 & -0.26620 & 0.18172 \\
\hline Thursday & 0.00273 & 0.00144 & 0.05292 & 7.81843 & 0.64555 & -0.20909 & 0.28052 \\
\hline Friday & 0.00002 & 0.00281 & 0.04450 & 4.76227 & -0.86813 & -0.23111 & 0.14233 \\
\hline Saturday & 0.00239 & 0.00194 & 0.03753 & 3.90242 & -0.46831 & -0.17221 & 0.14054 \\
\hline Sunday & 0.00199 & 0.00084 & 0.03334 & 4.00877 & -0.03321 & -0.16687 & 0.13089 \\
\hline
\end{tabular}

The results of table 1 indicate that the average daily return for Monday is higher 
than the average daily return earned during any other day of the week. The maximum return is also earned on Monday during the sample period. The maximum loss of $26.62 \%$ on a particular trading day is observed on Wednesday. The standard deviation for Thursday is $5.29 \%$, which is higher as compared to any other day of the week and suggests that the return generation process is more volatile on Thursday. The returns of Monday and Thursday are positively skewed, whereas returns of all other days of the week are negatively skewed. It indicates that positive returns are dominant on Monday and Thursday and negative returns dominate for the rest of the days of the week. The returns of all days of the week are leptokurtic which shows the peakness of the data. It implies a high-risk high return situation.

The statistical behaviour of monthly Bitcoin returns for all months of the year from 2013 to 2017 is presented in Table 2.

Table 2: Descriptive statistics of monthly bitcoin returns for the period of 2013 to 2017

\begin{tabular}{|l|c|c|c|c|c|c|c|}
\hline & Mean & Median & Std. Dev. & Kurtosis & Skewness & Minimum & Maximum \\
\hline January & -0.10976 & -0.07402 & 0.21194 & -0.48503 & -0.77664 & -0.38690 & 0.09592 \\
\hline February & 0.02762 & 0.16385 & 0.29403 & 3.94077 & -1.98184 & -0.41276 & 0.19554 \\
\hline March & -0.09236 & -0.07263 & 0.06577 & 0.94135 & -1.27677 & -0.18389 & -0.04029 \\
\hline April & 0.06200 & 0.02619 & 0.12119 & 0.59523 & 1.21274 & -0.03360 & 0.22921 \\
\hline May & 0.25113 & 0.25082 & 0.23560 & -0.66924 & 0.00667 & -0.02556 & 0.52844 \\
\hline June & 0.03765 & 0.08161 & 0.19856 & 2.50584 & -1.38607 & -0.28913 & 0.23675 \\
\hline July & 0.03152 & 0.07884 & 0.10614 & -2.77698 & -0.34260 & -0.08743 & 0.14757 \\
\hline August & 0.04722 & -0.08205 & 0.30996 & -1.29038 & 0.83801 & -0.21292 & 0.49211 \\
\hline September & -0.04509 & -0.01751 & 0.10620 & 0.78795 & -1.08919 & -0.21084 & 0.05785 \\
\hline October & 0.22363 & 0.28585 & 0.23001 & 0.55934 & -1.10492 & -0.13428 & 0.42777 \\
\hline November & 0.50523 & 0.18316 & 0.69148 & 3.97259 & 1.98189 & 0.06184 & 1.71135 \\
\hline December & 0.02857 & 0.13202 & 0.30631 & -1.33309 & -0.71751 & -0.40406 & 0.32449 \\
\hline
\end{tabular}

The results indicate that November is high risk and higher return month. The average monthly return for November is $50.52 \%$ which is higher than any other month of the year. Similarly, a higher standard deviation of $69.14 \%$ is observed as compared to other months of the year. The maximum loss is reported in the month of February. Also, the monthly returns have positive as well as negative skewness values. The positive 
skewness values are observed for the month of April, May, August, and November; which suggests large positive returns are dominant in these months. The negative skewness values are reported during other months of the year that indicates that large negative returns are dominant in these months. The returns series of February and November are leptokurtic and indicate these series observe high peak than the normal distribution. The Kurtosis values for all other months are less than 3 and show platykurtic behaviour. The returns series except February and November are flat and have a thinner tail. The regression results of the day of the week effect are shown in table 3 .

\begin{tabular}{|c|c|c|c|}
\hline \multicolumn{5}{|c|}{ Table 3: Results of the day of the week anomaly for the period of 2013 to 2017 } \\
\hline Day of the week & Coefficient & t-Statistic & Prob. \\
\hline Monday & $0.0091 * * *$ & 3.2488 & 0.0012 \\
\hline Tuesday & 0.0039 & 1.4013 & 0.1613 \\
\hline Wednesday & -0.0005 & -0.1710 & 0.8642 \\
\hline Thursday & 0.0027 & 0.9727 & 0.3309 \\
\hline Friday & 0.0000 & 0.0059 & 0.9953 \\
\hline Saturday & 0.0024 & 0.8525 & 0.3941 \\
\hline Sunday & 0.0020 & 0.7111 & 0.4771 \\
\hline Adjusted R-squared & 0.000991 & & \\
\hline Durbin-Watson stat & 1.986565 & & \\
\hline
\end{tabular}

Note. $* * *$ indicates significance at $1 \%$,

The results indicate that the distribution of returns for Monday is different from other days of the week. It indicates that the return generation process is continuous during calendar time. The results assert a clear rejection of weak-form EMH in the Bitcoin market and suggest that anomaly occurs on weekends even though the Bitcoin market operates 24/7. The similar patterns for the currency market also indicate that these anomalies occur at the start of the week i.e., Monday and the end of the week i.e., Friday (Kurihara, 2011). The results of the current study do not support the findings of Kurihara and Fukushima (2017). They report that the returns of Tuesday, Wednesday and Friday are different from other days of the week. The current study suggests that the returns of Monday are different from other days of the week. The findings suggest that there exists the Monday effect even the Bitcoin market continuously works and no concept of holidays in this market.

The results of the month of the year are shown in table 4 . 


\begin{tabular}{|c|c|c|c|}
\hline \multicolumn{3}{|c|}{ Table 4: Results of the month of the year anomaly for the period from $\mathbf{2 0 1 3}$ to 2017} \\
\hline The month of the Year & Coefficient & t-Statistic & Prob. \\
\hline January & -0.1098 & -0.7434 & 0.4613 \\
\hline February & 0.0276 & 0.1871 & 0.8525 \\
\hline March & -0.0924 & -0.6255 & 0.5349 \\
\hline April & 0.0620 & 0.4199 & 0.6766 \\
\hline May & $0.2511^{* *}$ & 1.7009 & 0.0962 \\
\hline June & 0.0377 & 0.2851 & 0.7769 \\
\hline July & 0.0315 & 0.2387 & 0.8125 \\
\hline August & 0.0472 & 0.3576 & 0.7224 \\
\hline September & -0.0451 & -0.3415 & 0.7344 \\
\hline October & $0.2236^{* *}$ & 1.6934 & 0.0976 \\
\hline November & $0.5052^{* * *}$ & 3.8258 & 0.0004 \\
\hline December & 0.0286 & 0.2163 & 0.8297 \\
\hline Adjusted R-squared & 0.105666 & & \\
\hline Durbin-Watson stat & 2.009714 & & \\
\hline
\end{tabular}

Note. $* * *$ indicates significance at 1\%, ** indicates significance at $5 \%, *$ indicates significance at 10

The results indicate that the distribution of returns for all months of the year is different and suggests that the return generation process is not the same for all the months. The results indicate that the return generation process is significantly different for the month of November at $\alpha=.01$ and for May and October at $\alpha=.10$. The results for the month of the year effect reject the market efficiency in the Bitcoin market and suggest that month of the year anomaly exists.

\section{CONCLUSION}

The study empirically investigates the seasonality in the returns of the Bitcoin market for the period from 2013 to 2017 . The results of the study suggest that calendar anomalies are present in the market any day of the week and month of the year effect exists. The statistical results indicate the behavior of Monday returns is different and investors can earn higher returns on Monday from other days of the week. The results of the day of the week are not in line with the findings of Kurihara and Fukushima (2017), their study suggested the returns of Tuesday, Wednesday and Friday are different from other days of the week. Similarly, the behaviour of returns earned in the month of November is different and earn higher returns in November from other months of the year. These abnormalities in returns are also observed in May and October. The study 
rejects the efficient market hypothesis which asserts that in an informationally efficient market no free lunches are possible therefore no abnormal gains can be fetched. Therefore, the results of the study conclude that statistical results violate the assumption of market efficiency and predictability element exists in the Bitcoin market, hence, it provides an opportunity for the investors to exploit the market from its predictable behaviour.

\section{REFERENCES}

Aharon, D. Y., \& Qadan, M. (2018). Bitcoin and the day-of-the-week effect. Finance Research Letters.

Aumeboonsuke, V., \& Dryver, A. L. (2014). The importance of using a test of weak-form market efficiency that does not require investigating the data first. International Review of Economics \& Finance, 33, 350-357.

Aydoğan, K., \& Booth, G. G. (2010). Calendar Anomalies in the Turkish Foreign Exchange Markets. Applied Financial Economics, 13, 353-360.

Bachelier, L. (1900). Théorie de la spéculation. Gauthier-Villars.

Bariviera, A. F. (2017). The inefficiency of Bitcoin revisited: a dynamic approach. Economics Letters, 1-4.

Berument, H., \& Kiymaz, H. (2001). The day of the week effect on stock market volatility. Journal of Economics and Finance, 25, 181-193.

Bradbury, D. (2013). The problem with Bitcoin. Computer Fraud \& Security, 5-8.

Brandvold, M., Molnár, P., Vagstad, K., \& Valstad, O. C. A. (2015). Price discovery on Bitcoin exchanges. Journal of International Financial Markets, Institutions, and Money, 36, 18-35.

Caporale, G. M., Gil-Alana, L., \& Plastun, A. (2018). Persistence in the cryptocurrency market. Research in International Business and Finance, 46, 141-148.

Chan, S., Chu, J., Nadarajah, S., \& Osterrieder, J. (2017). A Statistical Analysis of Cryptocurrencies. Journal of Risk and Financial Management, 1-23.

Cheah, E.-T., \& Fry, J. (2015). Speculative bubbles in Bitcoin markets? An empirical investigation into the fundamental value of Bitcoin. Economics Letters, 32-36.

Cheung, A. W.-K., Roca, E., \& Su, J.-J. (2015). Crypto-currency bubbles: an application of the Phillips-Shi-Yu (2013) methodology on Mt. Gox bitcoin prices. Applied Economics, 2348-2358.

Clark, P. K. (1973). A Subordinated Stochastic Process Model with Finite Variance for Speculative Prices. Econometrica, 41, 135-155.

Cooper, M. J., McConnell, J. J., \& Ovtchinnikov, A. V. (2006). The other January effect. Journal of Financial Economics, 82, 315-341.

Corbet, S., Meegan, A., Larkin, C., Lucey, B., \& Yarovaya, L. (2018). Exploring the dynamic relationships between cryptocurrencies and other financial assets. Economics Letters, 165, 28-34.

Cross, F. (1973). The Behavior of Stock Prices on Fridays and Mondays. Financial Analysts Journal, 29, 67-69.

Dyhrberg, A. H. (2016). Bitcoin, gold and the dollar - A GARCH volatility analysis. Finance Research Letters, 85-92.

Fama, E. F. (1965). The Behavior of Stock-Market Prices. The Journal of Business, 38, 
34-105.

Fama, E. F. (1970). Efficient Capital Markets: A Review of Theory and Empirical Work. The Journal of Finance, 25, 383-417.

Fraz, A., \& Hassan, A. (2016). Testing Information Efficiency using Random Walk Model: Empirical evidence from Karachi stock exchange. Journal of Managerial Sciences, 249-266.

French, K. R. (1980). Stock returns and the weekend effect. Journal of Financial Economics, 8, 55-69.

Fry, J., \& Cheah, E. T. (2016). Negative bubbles and shocks in cryptocurrency markets. International Review of Financial Analysis, 47, 343-352.

Glaser, F., Zimmermann, K., Haferkorn, M., Weber, M. C., \& Siering, M. (2014). Bitcoin Asset or Currency? Revealing Users' Hidden Intentions.

Hencic, A., \& Gouriéroux, C. (2015). Noncausal autoregressive model in application to Bitcoin/USD exchange rates. Econometrics of Risk, 17-39.

Katsiampa, P. (2017). Volatility estimation for Bitcoin: A comparison of GARCH models. Economics Letters, 3-6.

Kiymaz, H., \& Berument, H. (2003). The day of the week effect on stock market volatility and volume: International evidence. Review of Financial Economics, 12, 363380.

Katsiampa, P. (2017). Volatility estimation for Bitcoin: A comparison of GARCH models. Economics Letters, 158, 3-6.

Kurihara, Y. (2011). Is the Tokyo Foreign Exchange Market Efficient from Two Perspectives of Forward Bias and Anomaly?" Modern Economy. Modern Economy, 2, 597-601.

Kurihara, Y., \& Fukushima, A. (2017). The Market Efficiency of Bitcoin: A Weekly Anomaly Perspective. Journal of Applied Finance \& Banking, 7, 57-64.

Nadarajah, S., \& Chu, J. (2017). On the inefficiency of Bitcoin. Economics Letters, 6-9.

Nakamoto, S. (2009). Bitcoin: A Peer-to-Peer Electronic Cash System.

Robins, R. P., \& Smith, G. P. (2017). On Unmodeled Breaks in the Turn of the Year, Turn of the Month, and January Effects. The Financial Review, 52, 725-747.

Rozeff, M. S., \& Kinney, W. R. (1976). Capital market seasonality: The case of stock returns. Journal of Financial Economics, 3, 379-402.

Selgin, G. (2015). Synthetic commodity money. Journal of Financial Stability, 92-99.

Thies, S., \& Molnár, P. (2018). Bayesian change point analysis of Bitcoin returns. Finance Research Letters, 27, 223-227.

Troster, V., Tiwari, A. K., Shahbaz, M., \& Macedo, D. N. (2018). Bitcoin returns and risk: A general GARCH and GAS analysis. Finance Research Letters. Urquhart, $A$. (2016). The inefficiency of Bitcoin. Economics Letters, 80-82.

Yamori, N., \& Kurihara, Y. (2004). The day-of-the-week effect in foreign exchange markets: multi-currency evidence. Research in International Business and Finance, 18, 51-57. 